\title{
Analgesic Efficacy of Low Intensity Laser Therapy in a Monosodium Iodoacetate-induced Osteoarthritic Rat Model
}

\author{
Gyeyeop Kim, PhD, VMD ${ }^{1)}$, EunJung Kim, PhD, $\mathrm{PT}^{2)}$ \\ 1) Department of Physical Therapy, College of Health and Welfare, Dongshin University \\ 2) Department of Physical Therapy, Nambu University: Chemdan Jungang 1-ro, Gwangsan-gu, \\ Gwangju, 506-706, Republic of Korea. TEL: +82 62-970-0235, FAX: +82 62-970-0492
}

\begin{abstract}
Purpose] This study evaluated the analgesic efficacy of low-intensity laser therapy (LILT) in a monosodium iodoacetate (MIA)-induced arthritis rat model. [Subjects and Method] Thirty Sprague-Dawley rats were randomly divided into 3 groups with 10 rats each: the normal, control, and LILT groups. The LILT group was treated with LILT using a gallium-aluminum-arsenide diode laser during the 3 weeks. Each group had 10 rats. All treatments were applied once a day, 5 days a week, for a total experimental period of 21 days. Weight-bearing shift, paw withdrawal threshold (PWT), and paw withdrawal latency were used as outcome measures. [Results] The hind paw weight-bearing shift, PWT, and paw withdrawal latency of rats in the control group were significantly lower than those in the normal group. In the LILT group, the weight-bearing shift, PWT, and paw withdrawal latency were significantly greater than those in the control group. [Conclusion] LILT reduces pain related behaviors of MIAinduced osteoarthritis in rats.

Key words: Low intensity laser, Osteoarthritis, Pain
\end{abstract}

(This article was submitted Sep. 19, 2012, and was accepted Nov. 3, 2012)

\section{INTRODUCTION}

Osteoarthritis (OA) one of the most common forms of degenerative arthritis, is caused by a progressive loss of articular cartilage, new bone formation at the joint margins, and synovial proliferation. It is also involves the subchondral bone, ligaments, synovial membrane and periarticular muscle. OA can result in a loss of joint function, disability, chronic pain, and diminished quality of $\operatorname{life}^{1-3)}$. Pain is the predominant clinical feature in OA patients and often involves hyperalgesia, referred pain, and ongoing pain; it is also the driving factor for visiting a primary care physician $^{4,5)}$. Knee OA is generally classified as inflammatory nociceptive and neuropathic pain. Regarding the mechanism of neuropathic pain in knee OA, it is highly possible that knee joint pain occurs in association with damage to nerves innervating subchondral bone because of its weight-bearing surface in late stage $\mathrm{OA}^{6}$. However, the pathophysiology associated with OA, especially in the knee joint, involves complex structural changes; moreover, the pain related to OA is poorly understood ${ }^{7}$.

Knee OA patient pain is primary treated with lifestyle changes, followed by pharmacological interventions including acetaminophen, non-steroidal anti inflammatory drugs, topical agents, and intra-articular steroid injection ${ }^{8,9)}$ as well as non-pharmacological interventions such as transcutaneous electrical nerve stimulation ${ }^{10)}$, microwave diathermy ${ }^{11)}$, and exercise ${ }^{12)}$. These interventions currently aim to provide symptomatic relief of the pain and inflam- mation associated with osteoarthritis to increase joint function.

Intra-articular space injection of monosodium iodoacetate (MIA) induces chondrocyte death in the articular cartilage of both rodent and non-rodent species ${ }^{13)}$. The pathological OA rat model involves injecting MIA into the rat femorotibial joint space, this model produces a linear pathology similarities to that of human $\mathrm{OA}^{14,15)}$ as well as significant pain-related behavior ${ }^{16,17)}$. This model is an established and well-characterized preclinical model of osteoarthritis.

Low-intensity laser therapy (LILT) has numerous clinical benefits such as improved tissue metabolism, pain reduction via reduce inflammation, blocked nerve sensitivity via the anagogic effect, and nerve regeneration at the tissue level ${ }^{18-20)}$. Low-level laser photons can penetrate deep into the body through the skin, muscles, tendons, ligaments, nerves, and even bones, in order to pinpoint and target painful and damaged areas ${ }^{21)}$. LILT is also used to control pain in different musculoskeletal conditions. Therefore, LILT is a commonly recommended physical therapy to treat arthritis ${ }^{22,23)}$. However, the results of experimental and clinical studies on LILT are conflicting despite its widespread use.

Therefore, the present study was designed to investigate the effectiveness and mechanisms of LILT on the attenuation of OA pain behavior in a rat model. 


\section{METHODS}

This study involved 30 male Sprague-Dawley rats, each weighing $150-160 \mathrm{~g}$. The rats were housed at a temperature of $25.0^{\circ} \mathrm{C} \pm 1.0^{\circ} \mathrm{C}$ and a humidity level of $50 \pm 5 \%$ with a 12-h light-dark cycle; they had free access to food and water. The general health of the animals was monitored. A total of 30 rats were used in this study, and they were randomly divided into 3 groups of 10 rats after MIA-induced arthritis (Table 1). All experimental procedures in this study were reviewed and approved by the Ethical Review Committee of Dongshin University.

After the rats were acclimatized for 1 week, they were given a single intra-articular injection of MIA via the infrapatella ligament of the left knee at a dose of $4.8 \mathrm{mg}$ dissolved in $60 \mu \mathrm{L}$ sterile saline. The rats of the normal group were given a single intra-articular injection of equal volume of sterile saline. Substantial inflammation of the synovial joints was observed in the MIA-injected rat up to 5 days after the MIA injection.

A gallium-aluminum-arsenide diode laser with the following characteristics was used for LILT: wavelength, $850 \mathrm{~nm}$; power output, $200 \mathrm{mV}$; wave pulse, $16 \mathrm{~Hz}$; and spot area, $0.07 \mathrm{~cm}^{2}$. The therapeutic point was positioned medial to the patellar ligament, and the treatment was applied on towards the joint surface of the femur. The LILT group was treated with $3.6 \mathrm{~J} / \mathrm{cm}^{2}$ for $20 \mathrm{~s}$ in the periarticular region of both hind paws 5 times per week over 21 days following arthritis induction. The researchers wore protective eyeglasses during the laser treatment for safety. In the control group, the diode laser was applied in the same way, but the device was turned off during therapy sessions.

Tactile sensory thresholds were determined using calibrated von Frey filaments. The development of mechanical allodynia was assessed using von Frey monofilaments described previously ${ }^{24)}$. Von Frey monofilaments were applied to the plantar surface of both hind paws for $3 \mathrm{~s}$. Once a withdrawal reflex was established, the paw was retested with the next descending von Frey monofilament until no response occurred. The lowest monofilament weight that elicited a withdrawal reflex was recorded as the paw withdrawal threshold (PWT). When the instrument was activated, a fine plastic monofilament advanced at a constant speed and touched the paw in the proximal metatarsal region.

The method of Hargreaves et al. ${ }^{25)}$ was used to assess paw withdrawal latency to a thermal nociceptive stimulus as described previously ${ }^{26}$. Baseline latencies were established at $20 \mathrm{~s}$ to allow a sufficient window for the detection of possible hyperalgesia. A maximal cutoff of $30 \mathrm{~s}$ was used to prevent tissue damage. Hind paw withdrawal latency and withdrawal threshold differences were assessed on days 1, 7, 14, and 21 after LILT.

Hind-limb weight bearing was measured using an incapacitance tester that included a dual-channel weight average. On day 21 , the rats were carefully placed in a plastic chamber. The force exerted by each hind limb was averaged over a 3-s period. The mean of 3 readings was recorded. The percentage of weight distributed onto the treated (i.e., ipsilateral) hind limb was calculated using the following
Table 1. Experimental group design

\begin{tabular}{ll}
\hline Group (Total $\mathrm{n}=30)$ & Treatment \\
\hline Normal group $(\mathrm{n}=10)$ & $\begin{array}{l}\text { Non-arthritis group } \\
\text { Placebo laser therapy for } 20 \text { second }\end{array}$ \\
Control group ( $\mathrm{n}=10)$ & $\begin{array}{l}\text { at the peri-articular area after MIA- } \\
\text { induced arthritis }\end{array}$ \\
& $\begin{array}{l}\text { LILT } 3.6 \mathrm{~J} / \mathrm{cm}^{2} \text { for } 20 \text { seconds at } \\
\text { the peri-articular area after MIA- } \\
\text { induced arthritis }\end{array}$ \\
\hline
\end{tabular}

${ }^{a}$ Low Intensity Laser Therapy

equation: (weight on left leg/weight on right leg) $\times 100$.

Data analysis was performed using SPSS for Windows version 17.0 (SPSS Inc., Chicago, IL, USA). All the data are expressed as the mean \pm SD of 3 replicates. Differences between 2 groups were tested by one-way ANOVA followed by Dunnett's post hoc analysis when a significant difference was detected. P values less than 0.05 at a $95 \%$ confidence level were considered significant.

\section{RESULTS}

As shown in Table 2, the paw withdrawal threshold decreased significantly in the MIA-induced arthritic group compared to the normal group $(\mathrm{p}<0.05)$. The PWT of the LILT increased significantly after 7 days compared with that of the control group $(\mathrm{p}<0.05)$. The effects of LILT on the withdrawal latency of MIA-induced arthritic rats are shown in Table 3. The LILT group had significantly longer withdrawal latency than the control group assessed at 14 and 21 days after LILT began $(p<0.05)$. The effects of LILT on the hind-limb weight bearing of MIA-induced arthritic rats are shown in Table 4 . The hind-limb weight-bearing rate of the ipsilateral limb was significantly lower in the MIA-treated groups than the normal group $(\mathrm{p}<0.05)$. After 21 days, the LILT group exhibited significant recovery of hind-limb weight bearing $(\mathrm{p}<0.05)$.

\section{DISCUSSION}

The present study investigated the therapeutic effects of LILT on the PWT, paw withdrawal latency, and weightbearing shift in a MIA-induced OA rat model. The results indicate that daily treatment of OA rats with LILT significantly increased joint mobility and decreased the secondary tactile allodynia, mechanical hyperalgesia, and the hind-limb weight-bearing of the affected knee joint.

Knee OA is a common chronic degenerative disease characterized by loss of articular cartilage components, and affects the entire joint structure including the synovial membrane, fat pad, and subchondral bone ${ }^{27)}$. MIA injection has been reported to cause joint pathology by the inhibiting glycolysis, thereby targeting avascular cartilage and causing chondrocyte death similar to human $\mathrm{OA}^{14)}$. Normally quiescent chondrocytes as well as synovial cells respond to repetitive excess mechanical loading via stressinduced intracellular signals that mediate the production of 
Table 2. Effect of low intensity laser therapy on the paw withdrawal thresholds in MIA-induced arthritis rats (g)

\begin{tabular}{lcccc}
\hline & 1 day & 7 days & 14 days & 21 days \\
\hline Normal group & $20.50 \pm 5.80$ & $21.60 \pm 5.68$ & $23.80 \pm 4.64$ & $24.90 \pm 3.48$ \\
Control group & $5.60 \pm 1.58^{*}$ & $5.60 \pm 1.63^{*}$ & $5.60 \pm 1.27^{*}$ & $5.40 \pm 1.35^{*}$ \\
LILT $^{\text {a }}$ group & $5.60 \pm 1.58$ & $6.60 \pm 1.65$ & $9.00 \pm 1.05^{* *}$ & $10.90 \pm 3.11^{* *}$ \\
\hline
\end{tabular}

aLow Intensity Laser Therapy, data were presented as mean $\pm \mathrm{SD},{ }^{*}$ : $\mathrm{p}<0.05$ as compared to normal group, ${ }^{* *}: \mathrm{p}<0.05$ as compared to control group

Table 3. Effect of low intensity laser therapy on the paw withdrawal latency in MIA-induced arthritis rats (s)

\begin{tabular}{lcccc}
\hline & 1 day & 7 days & 14 days & 21 days \\
\hline Normal group & $12.70 \pm 3.65$ & $12.40 \pm 2.22$ & $13.80 \pm 1.93$ & $14.60 \pm 1.26$ \\
Control group & $3.00 \pm 0.61^{*}$ & $3.02 \pm 0.73^{*}$ & $3.40 \pm 0.70^{*}$ & $3.95 \pm 0.89^{*}$ \\
LILT $^{\text {a }}$ group & $2.87 \pm 0.70$ & $4.45 \pm 1.23$ & $6.60 \pm 1.26^{* *}$ & $9.30 \pm 2.58^{* *}$ \\
\hline
\end{tabular}

${ }^{a}$ Low Intensity Laser Therapy, data were presented as mean $\pm \mathrm{SD},{ }^{*}: \mathrm{p}<0.05$ as compared to normal group, ${ }^{* *}: \mathrm{p}<0.05$ as compared to control group

proinflammatory mediators such as cytokines and cartilagedegrading proteinase ${ }^{28)}$.

Pain fibers are present in the synovium, ligaments, bone, muscle and meniscus of the knee. The MIA model of OA, in which a single injection of the irreversible NADPH inhibitor, sodium monoiodoacetate, is made into the joint space, provides a model of the painful and structural components of human OA in rodents. In the MIA-induced OA model, synovial inflammation occurs during the first week after MIA treatment and resolves 1 week later ${ }^{29)}$. In addition, the contribution of neuropathic pain and other neurologic mechanisms to the development of pain in this model remain to be elucidated. The significant decrease in PWT observed in the present our study indicates tactile allodynia pathogenesis, which is consistent with a previous study ${ }^{30)}$. This decrease is considered to result from allodynia derived from central sensitization; the increase in afferent signaling from the joint nociceptors to the spinal cord neurons results in increased sensitivity of the spinal cord neurons to input from the joint, rendering the spinal cord neurons hyperexcitable ${ }^{31)}$. LILT can relieve pain, induce collagen proliferation, have anti-inflammation effects, enhance circulation and stimulates peripheral nerves ${ }^{32}$. In 1994, Stelian et al. randomly assigned 50 patients with knee OA to receive treatment with red $(630 \mathrm{~nm})$, infrared $(830 \mathrm{~nm})$ or placebo laser light emitters ${ }^{33)}$. They observed significant functional improvement and pain reduction in the laser therapy groups, but not in the control group. On the basis of these results, they concluded that low-power laser therapy is effective for pain relief and improving functional ability. Tascioglu et al. ${ }^{34)}$ used a gallium-aluminum-arsenide laser with a wavelength of $830 \mathrm{~nm}$ for the treatment of knee OA. However, they found no significant difference between laser and placebo-treated groups with respect to any measure of pain score including the visual analogue scale ${ }^{34)}$.

The present study has some limitations. First, MIA-induced $\mathrm{OA}$ is chemically induced animal model. Further research should study by other OA pathological model to clarify the details. Second, the pain behavioral evaluation for tactile
Table 4. Effects of low intensity laser therapy on hindlimb weight bearing rate of the ipsilateral limb in MIA-induced arthritis rats on 21 days

\begin{tabular}{lc}
\hline & Hind-limb weight bearing rate (\%) \\
\hline Normal group & $96.96 \pm 10.00 \%$ \\
Control group & $50.15 \pm 4.74 * \%$ \\
LILT ${ }^{\text {a group }}$ & $63.13 \pm 3.62 * * \%$ \\
\hline
\end{tabular}

${ }^{a}$ Low Intensity Laser Therapy, data were presented as mean $\pm \mathrm{SD}, *$ : $\mathrm{p}<0.05$ as compared to normal group, $* *$ : $\mathrm{p}<0.05$ as compared to control group

allodynia with von Frey hairs can be somewhat inaccurate and depends on the subjective responses of the animals. To analyze the behavior of rats objectively to analyze their behavior by using other methods such as evaluating weightbearing in free-moving animals, as well as response to heat and direct measurement of pressure on the knee ${ }^{35,36)}$. Third, our present study had a small sample size. Therefore, further investigation with a larger sample size may be needed to clarify whether analgesic effect actually occurred.

The present results demonstrate that treatment with LILT increased paw withdrawal latency and threshold on day 14 after MIA-induced OA. In addition, the hind-paw weight shift recovered on day 21 after LILT. Therefore, the present results indicate that LILT exerts an analgesic effect by reducing the synovial inflammation induced by MIA injection, which causes peripheral and central sensitization $^{37)}$. More trials with laser subject numbers are needed to precisely determine the optimal treatment procedure for LILT as well as possible interactions regarding the treatment of chronic pain associated with OA.

\section{REFERENCES}

1) Abramson SB, Attur M: Developments in the scientific understanding of osteoarthritis. Arthritis Res Ther, 2009, 11: 227. [Medline]

2) Loeser RF: Molecular mechanisms of cartilage destruction in osteoarthritis. J Musculoskelet Neuronal Interact, 2008, 8: 303-306. [Medline]

3) Read SJ, Dray A: Osteoarthritic pain: a review of current, theoretical and emerging therapeutics. Expert Opin Investig Drugs, 2008, 17: 619-640. 
[Medline] [CrossRef]

4) Gwilym SE, Keltner JR, Warnaby CE, et al.: Psychophysical and functional imaging evidence supporting the presence of central sensitization in a cohort of osteoarthritis patients. Arthritis Rheum, 2009, 61: 1226-1234 [Medline] [CrossRef]

5) Hawker GA: Experiencing painful osteoarthritis: what have we learned from listening? Curr Opin Rheumatol, 2009, 21: 507-512. [Medline] [CrossRef]

6) Ohtori S, Orita S, Yamashita M, et al.: Existence of a neuropathic pain component in patients with osteoarthritis of the knee. Yonsei Med J, 2012 53: 801-805. [Medline] [CrossRef]

7) Felson DT: The sources of pain in knee osteoarthritis. Curr Opin Rheumatol, 2005, 17: 624-628. [Medline] [CrossRef]

8) Dieppe PA, Lohmander LS: Pathogenesis and management of pain in osteoarthritis. Lancet, 2005, 365: 965-973. [Medline] [CrossRef]

9) Sarzi-Puttini P, Cimmino MA, Scarpa R, et al.: Do physicians treat symptomatic osteoarthritis patients properly? Results of the AMICA experience. Semin Arthritis Rheum, 2005, 35: 38-42. [Medline] [CrossRef]

10) Beckwée D, De Hertogh W, Lievens P, et al.: Effect of tens on pain in relation to central sensitization in patients with osteoarthritis of the knee: study protocol of a randomized controlled trial. Trials, 2012, 13: 21 [CrossRef]

11) Rabini A, Piazzini DB, Tancredi G, et al.: Deep heating therapy via microwave diathermy relieves pain and improves physical function in patients with knee osteoarthritis: a double-blind randomized clinical trial. Eur J Phys Rehabil Med, 2012, 48: 1-11.

12) Nijs J, Kosek E, Vanoosterwijck J, et al.: Dysfunctional endogenous analgesia during exercise in patients with chronic pain: to exercise or no to exercise? Pain Physician, 2012, 15: ES205-ES213. [Medline]

13) Dunham J, Hoedt-Schmidt S, Kalbhen DA: Prolonged effect of iodoacetate on articular cartilage and its modification by an anti-rheumatic drug. Int J Exp Pathol, 1993, 74: 283-289. [Medline]

14) Guzman RE, Evans MG, Bove S, et al.: Mono-iodoacetate-induced histologic changes in subchondral bone and articular cartilage of rat femorotibial joints: an animal model of osteoarthritis. Toxicol Pathol, 2003, 31 619-624. [Medline]

15) Pomonis JD, Boulet JM, Gottshall SL, et al.: Development and pharmacological characterization of a rat model of osteoarthritis pain. Pain, 2005, 114: 339-346. [Medline] [CrossRef]

16) Bove SE, Laemont KD, Brooker RM, et al.: Surgically induced osteoarthritis in the rat results in the development of both osteoarthritis-like joint pain and secondary hyperalgesia. Osteoarthritis Cartilage, 2006, 14: 1041-1048. [Medline] [CrossRef]

17) Combe R, Bramwell S, Field MJ: The monosodium iodoacetate model of osteoarthritis: a model of chronic nociceptive pain in rats? Neurosci Lett, 2004, 370: 236-240. [Medline] [CrossRef]

18) da Rosa AS, dos Santos AF, da Silva MM, et al.: Effects of low-level laser therapy at wavelengths of 660 and $808 \mathrm{~nm}$ in experimental model of osteoarthritis. Photochem Photobiol, 2012, 88: 161-166. [Medline] [CrossRef]

19) Pallotta RC, Bjordal JM, Frigo L, et al.: Infrared (810-nm) low-level laser therapy on rat experimental knee inflammation. Lasers Med Sci, 2012, 27: 71-78. [Medline] [CrossRef]

20) Medalha CC, Di Gangi GC, Barbosa CB, et al.: Low-level laser therapy improves repair following complete resection of the sciatic nerve in rats.
Lasers Med Sci, 2012, 27: 629-635. [Medline] [CrossRef]

21) Tuner J, Hode L: The laser therapy handbook. Sweden: Prima Books, 2004, pp 41-42.

22) Ye L, Kalichman L, Spittle A, et al.: Effects of rehabilitative interventions on pain, function and physical impairments in people with hand osteoarthritis: a systematic review. Arthritis Res Ther, 2011, 13: R28. [Medline] [CrossRef

23) Alfredo PP, Bjordal JM, Dreyer SH, et al.: Efficacy of low level laser therapy associated with exercises in knee osteoarthritis: a randomized double-blind study. Clin Rehabil, 2012, 26: 523-533. [Medline] [CrossRef]

24) Sagar DR, Staniaszek LE, Okine BN, et al: Tonic modulation of spina hyperexcitability by the endocannabinoid receptor system in a rat model of osteoarthritis pain. Arthritis Rheum, 2010, 62: 3666-3676. [Medline] [CrossRef]

25) Hargreaves K, Dubner R, Brown F, et al.: A new and sensitive method for measuring thermal nociception in cutaneous hyperalgesia. Pain, 1988, 32: 77-88. [Medline] [CrossRef]

26) King $T$, Rao $S$, Vanderah $T$, et al.: Differential blockade of nerve injuryinduced shift in weight bearing and thermal and tactile hypersensitivity by milnacipran. J Pain, 2006, 7, 513-520. [Medline] [CrossRef]

27) Todhunter PG, Kincaid SA, Todhunter RJ, et al.: Immunohistochemical analysis of an equine model of synovitis-induced arthritis. Am J Vet Res, 1996, 57: 1080-1093. [Medline]

28) Goldring MB, Goldring SR: Osteoarthritis. J Cell Physiol, 2007, 213: 626-634. [Medline] [CrossRef]

29) Beyreuther B, Callizot N, Stöhr T: Antinociceptive efficacy of lacosamide in the monosodium iodoacetate rat model for osteoarthritis pain. Arthritis Res Ther, 2007, 9: R14. [Medline] [CrossRef]

30) Fernihough J, Gentry C, Malcangio M, et al.: Pain related behaviour in two models of osteoarthritis in the rat knee. Pain, 2004, 112: 83-93. [Medline] [CrossRef]

31) Schaible HG: Neurophysiology of nociception and pain reactions in inflammatory joint diseases. Rev Rhum Engl Ed, 1997, 64: 144S-145S. [Medline]

32) Gur A, Sarac AJ, Cevik R, et al.: Efficacy of $904 \mathrm{~nm}$ gallium arsenide low level laser therapy in the management of chronic myofascial pain in the neck: a double-blind and randomize-controlled trial. Lasers Surg Med, 2004, 35: 229-235. [Medline] [CrossRef]

33) Stelian J, Gil I, Habot B, et al.: Improvement of pain and disability in elderly patients with degenerative osteoarthritis of the knee treated with narrow-band light therapy. J Am Geriatr Soc, 1992, 40: 23-26. [Medline]

34) Tascioglu F, Armagan O, Tabak Y, et al.: Low power laser treatment in patients with knee osteoarthritis. Swiss Med Wkly, 2004, 134: 254-258. [Medline]

35) Ferreira-Gomes J, Adães S, Castro-Lopes JM: Assessment of movementevoked pain in osteoarthritis by the knee-bend and CatWalk tests: a clinically relevant study. J Pain, 2008, 9: 945-954. [Medline] [CrossRef]

36) Sekiguchi M, Shirasaka M, Konno S, et al.: Analgesic effect of percutaneously absorbed non-steroidal anti-inflammatory drugs: an experimenta study in a rat acute inflammation model. BMC Musculoskelet Disord, 2008, 9: 15. [Medline] [CrossRef]

37) Bove SE, Calcaterra SL, Brooker RM, et al.: Weight bearing as a measure of disease progression and efficacy of anti-inflammatory compounds in a model of monosodium iodoacetate-induced osteoarthritis. Osteoarthritis Cartilage, 2003, 11: 821-830. [Medline] [CrossRef] 